\title{
From our readers
}

\section{MATERIALS SCIENCE IN SECONDARY EDUCATION}

\author{
Clarification of funding sources for MRSEC initiatives
}

To the editor - Thank you for the coverage (Nature Materials 4, 105; 2005) of the teacher program held at the Materials Research Society's (MRS) 2004 Fall Meeting in Boston, as well as the other outreach initiatives advanced by the society in its efforts to improve public science literacy.

There appear to be a few attribution errors in your editorial with regards to funding sources of the initiatives mentioned. The National Science Foundation (NSF) division that supported the projects (Strange Matter, Materials World Modules) you described in the piece was the Division of Elementary, Secondary and Informal Education and not the Division of Materials Research (DMR). The teacher program that took place at the meeting was created through the efforts of the MRS and a few of its very proactive members who crafted and submitted the proposal to the NSF. This proposal, by the way, was indeed submitted to and supported by the DMR, although that was never mentioned in the article. Finally, it would have been much easier to have listed the Strange Matter Web site address - http://www. strangematterexhibit.com - than have your readers course their way through the Cornell website to find a link to Strange Matter.

If your political assessment at the end of the column is indeed correct, and the current administration's educational policies are stressing the flexibility of formal science education curricula, then the importance of the role of informal education programs and activities being created by the MRS and other groups is magnified.

Richard A. Souza

Project Manager — Strange Matter, Materials Research Society, 506 Keystone Drive, Warrendale, Pennsylvania 15086, USA

e-mail:souza@mrs.org

Non-MRSEC initiatives

To the editor - Your editorial in the February 2005 issue (Nature Materials 4, 105; 2005) rightly expressed the importance of materials science education at the high-school level, and the need for university researchers to help fight for flexibility in high-school curricula. We at Drexel University's College of Engineering are committed to these efforts. In fact, we wish to clarify your statement that "all of the projects [showcased at the November MRS meeting] were fruits of collaborations between university researchers and educators, mostly through Research Education Training (RET) programs sponsored by Materials Research Science and Engineering Centers (MRSEC)". This statement may discourage educators who are not affiliated with MRSECs from participating in this extremely important and exciting activity. There are 27 MRSECs in the US, whereas in reality, the National Science Foundation (NSF) has funded another 15 stand-alone RET programs. RET, by the way, stands for Research Experiences for Teachers, not Research Education Training.

Drexel University runs two NSF-sponsored RET programs without MRSEC support - indeed, four of the 90-plus teachers who attended the fall MRS meeting last year were from these programs, with one an invited speaker. Drexel's RET in Areas of Innovative and Novel (RETAIN) Technologies in the Delaware Valley program (http://www.coe.drexel.edu/ret/) began in 2003, and building on its successes, the RET-Nano program (http://nano.materials.drexel.edu/ret/), in collaboration with the University of Pennsylvania, began in 2004. These programs bring middle school, high school and community college teachers from the greater Philadelphia, Pennsylvania region into the lab for five weeks over the summer. The teachers become part of the university community and work with faculty, graduate and post-doctoral students, learn how to write proposals, perform experiments and conduct research. They present joint posters with their mentors in a well-attended event at the end of the term.

We want to make it clear to readers of Nature Materials by way of example that not only MRSECs run successful RET programs. Drexel and other universities are doing their part to enhance materials science and engineering education for the next generation. Smaller universities that do not have huge NSF-funded centres can also be successful in creating and running materials RETs.

Yury Gogotsi ${ }^{1}$, Holly Burnside ${ }^{1}$, Mun Young Choi $^{2}$ and Joanne Ferroni ${ }^{2}$

${ }^{1}$ Department of Materials Science and Engineering, ${ }^{2}$ Department of Mechanical Engineering and Mechanics, Drexel University, 3141 Chestnut St, Philadelphia, Pennsylvania 19104, USA

e-mail: gogotsi@drexel.edu 